\title{
Representações sociais de professores sobre afetividade
}

\author{
Teachers' social representations about affectivity
}

\author{
Marinalva Lopes RIBEIRO \\ France JUTRAS ${ }^{2}$
}

\begin{abstract}
Resumo
Este artigo discute a compreensão do conteúdo e da estrutura das representações sociais de professores do ensino fundamental sobre afetividade. Valendo-nos de instrumentos de coleta de dados variados (associação livre, entrevistas semi-estruturadas e triagens hierarquizadas sucessivas) concluímos que a afetividade, na prática educativa, é importante para potencializar a aprendizagem cognitiva dos alunos. Ademais, destacamos os elementos que podem constituir a dimensão central da referida representação.
\end{abstract}

Palavras-chave: afetividade; competência afetiva; relação educativa; representações sociais.

\begin{abstract}
This paper, which is based on our doctorate's thesis, discusses the elementary school teachers' social representations about affectivity, including their content and structure. The following three methods have been used to collected the data: 1) the Free Association, starting from the term "affectivity"; 2) semi-structured interviews; and 3) the hierarchical grouping. The results have shown how important is the affective dimension for students' learning process. Also it has brought out the possible elements to build up a central dimension of the affective representation.
\end{abstract}

Key words: affectivity; affective competence; teaching relationship; social representations.

Este artigo foi elaborado a partir da tese de Ribeiro (2004), com o objetivo geral de examinar a possível existência de representações sociais de afetividade nos professores do ensino fundamental. Os objetivos específicos visavam descrever como esses professores representam a competência afetiva na relação educativa e destacar a organização do conteúdo das representações de afetividade.

Pereira (1991); Araújo (1995); Cianfa (1996); Rodríguez, Plax e Kearney (1996); Testerman (1996);
Camargo (1997); Moll (1999); Côté (2002); Espinosa (2002) e Dias (2003). consideram que a dimensão afetiva contribui para a aquisição de atitudes positivas em relação a professores, às disciplinas por eles ministradas e, conseqüentemente, para a aprendizagem cognitiva dos alunos na sala de aula. Segundo Moll (1999, p.480), “a relação afetiva abre a relação com o saber". Para Codo e Gazzotti (1999, p.50), "é por meio do estabelecimento das relações afetivas que o processo de ensino-aprendizagem se realiza". Outros

1 Professora Doutora, Departamento de Educação, Universidade Estadual de Feira de Santana. Presidente Lincoln, 62, 44075-310, Feira de Santana, BA, Brasil. Correspondência para/Correspondence to: M.L.RIBEIRO.E-mait.<M.L.Ribeiro@Usherbrooke.ca>.

2 PhD, Departement de Psychologie, Université de Sherbrooke. Sherbrooke, QC, Canadá, J1K 2 R1. 
estudos mostram que as dificuldades na aprendizagem são produtos de não-ajustamentos entre professores e alunos e que, portanto, se constroem na sala de aula, nas interações pedagógicas (Altet, 1994; Hesse \& Weigand, 1994). Tal situação nos inquietou e nos instigou a explorar as razões que a explicam, e buscamos, então, conhecer as representações dos professores sobre afetividade e como os elementos constitutivos de tal representação são organizados.

Damásio (2000) e Assmann (1998) postulam que a aprendizagem depende da emoção e da valorização do corpo, motivo pelo qual os modelos que levam em conta apenas o aspecto intelectual são questionados. $\bigcirc$ discurso oficial sugere aos formadores dos professores a inclusão, nos programas de formação, de uma série de competências que ultrapassam a transmissão de um saber codificado numa disciplina (Brasil, 1991). Dentre outras, assegura o desenvolvimento da competência afetiva na relação educativa. No entanto, na prática dos professores e nos currículos dos cursos de formação, em diversas universidades brasileiras, as relações afetivas ainda não encontraram um lugar de equilíbrio no que concerne à dimensão cognitiva.

A afetividade, neste artigo, inscreve-se na relação educativa que se estabelece entre professor e alunos na sala de aula. Do nosso ponto de vista, a dimensão afetiva pode se desenvolver por meio da formação e é impulsionada pela expressão dos sentimentos e das emoções.

\section{O conceito de representações sociais}

As representações sociais compreendem formas de conhecimento do senso comum, quer dizer, organizadas e partilhadas socialmente, que servem para tornar compreensível e comum a realidade na qual os indivíduos de um grupo estão inseridos como sujeitos. Constituem-se de um conjunto organizado de conceitos, de proposições e de explicações criadas na vida cotidiana, durante as comunicações interpessoais dos grupos, para guiar os comportamentos e as práticas sociais de modo a traduzir a posição e a escala de valores de um indivíduo ou de uma coletividade.

Segundo Lage (2002), depois de 1970, coexistem duas abordagens para se estudar as representações sociais. A primeira, denominada societal, correspondente à orientação original de Serge Moscovici e de Denise Jodelet, estuda as representações em função do lugar em que o grupo ocupa na sociedade. A segunda, denominada estrutural, interessa-se pela maneira como um determinado objeto é construído do ponto de vista cognitivo. Nessa abordagem, as representações são estudadas a partir das respostas de um grupo homogêneo. Assim, não há interesse em relação ao aspecto social, mas, sem, à estrutura da própria representação. Uma representação é formada de elementos constitutivos (informações, crenças, opiniões e atitudes) (Abric, 1997), organizados e estruturados de acordo com a hipótese: "toda representação é organizada em torno de um núcleo central" (Abric, 1989; 1997). A essa proposição, mais tarde, Flament acrescenta a idéia de elementos periféricos (Moliner, 1995), uma vez que esses elementos, tomados como circunstanciais e acessórios em referência aos elementos do núcleo, eram provavelmente excluídos das preocupações dos pesquisadores.

Não obstante, de acordo com Lage (2002), o sistema periférico é mais rico e complexo do que o sistema central. Essa autora defende que as relações entre as representações e a prática podem ser examinadas a partir do estudo dos elementos periféricos e que descobrir o sistema central nos permitiria descobrir coisas óbvias, já conhecidas. No entanto, tal idéia não é partilhada por grande parte dos estudiosos da teoria das representações sociais. O núcleo central está ligado e determinado por condições históricas, sociológicas e ideológicas, marcado pela memória coletiva e pelo sistema de normas. Evolui de forma lenta. É ele quem atribui ou transforma a significação (um sentido, um valor) ao objeto representado; assegura a permanência e a perenidade da representação; permite compreender a realidade; dá homogeneidade ao grupo e define os princípios fundamentais em torno dos quais se constituem as representações; é simples, concreto, consensual, historicamente marcado, imagético e coerente; apresenta um valor simbólico, poder associativo, saliência e forte conexidade na estrutura. Não pode ser refutável (Moliner, 1995). 
O sistema periférico, contrariamente ao sistema central, é determinado pelo núcleo central ao qual está ligado e estabelece uma interface entre esse e a realidade concreta, na qual funciona a representação. É a parte mais acessível, flexível, adaptativa, viva e concreta da representação.

A teoria das representações sociais nos permite compreender o sentido que os professores, em sua prática, atribuem à afetividade e a natureza dos obstáculos que eles encontram para efetivar um processo educativo que leve em conta a dimensão afetiva. Por meio das representações, tomamos conhecimento das maneiras pelas quais os professores estabelecem relações com seus alunos e da influência dessas relações no processo educativo. Uma vez que as práticas se realizam em consonância com as representações dos professores, torna-se possível identificar, por meio do discurso desses profissionais, as concepções e as ações que interferem, positiva ou negativamente, nos resultados da aprendizagem dos alunos.

\section{Método}

A descrição das representações dos professores sobre afetividade nos leva a um nível de conhecimento que corresponde, particularmente, à descoberta e à exploração dos elementos constitutivos (conteúdo) dessas representações, da organização dos seus elementos (estrutura interna) e dos elementos do núcleo central (hierarquia). Escolhemos para participantes do estudo os professores em formação no curso de licenciatura em ensino fundamental oferecido pelo Departamento de Educação da Universidade Estadual de Feira de Santana, e que estão atuando em escolas públicas da região, com a possibilidade, portanto, do exercício da competência afetiva na relação educativa.

A coleta de dados fez-se em duas etapas. Na primeira, com o intuito de recolher os elementos constitutivos do conteúdo da representação de afetividade, convocamos cem desses professores para a realização de associações livres. Os participantes foram induzidos a escrever os substantivos, adjetivos, verbos e expressões sinônimas do termo indutor "afetividade", o que resultou em 249 evocações.
Dentre os professores que colaboraram na primeira etapa, recrutamos quinze para a segunda etapa, constituída de entrevistas semi-estruturadas e da organização de triagens hierarquizadas sucessivas. Buscando um testemunho completo por meio do discurso livre e espontâneo dos participantes, as entrevistas foram realizadas a partir de um guia composto por três eixos, cujas questões e "provocadores" (histórias reais vivenciadas por professores na sala de aula) versavam sobre o conteúdo da afetividade. Para organizar as triagens hierarquizadas sucessivas e conseguirmos uma classificação dos termos por ordem de importância, escolhemos as 32 palavras que apresentaram a maior freqüência entre as produzidas nas associações livres. Escrevemos essas palavras em fichas e solicitamos que os participantes as separassem em dois grupos: de um lado, as 16 palavras que Ihes pareciam as mais características de afetividade; do outro lado, as 16 palavras julgadas menos características. Após essa primeira operação, solicitamos que, procedendo de forma semelhante, selecionassem as oito palavras mais características e assim por diante até que cada um chegasse à palavra que, do ponto de vista pessoal, seria a mais específica de afetividade. Em seguida, cada participante foi convidado a justificar a sua escolha.

\section{Análise dos dados}

Para a análise dos dados, recorremos a metodologias mistas, as quais contêm elementos pertencentes às abordagens qualitativa e quantitativa. Assim, a fim de analisar as produções obtidas mediante as associações livres, extraímos, do total das 249 palavras evocadas, as 24 palavras (10\% do total) que obtiveram uma freqüência igual ou superior a dez. Em seguida, calculamos a mediana das freqüências, cujo resultado foi 16. Para efetuar o cálculo médio das evocações das palavras, retornamos às associações de cada participante e calculamos a ordem na qual cada palavra foi evocada. Somamos as evocações de cada palavra e calculamos a média de evocações dividindo esse total pela freqüência de cada termo. A partir da média de evocações de cada palavra, obtivemos a mediana 6,61. Finalmente, combinamos a freqüência do termo pelos cem participantes e a ordem de aparecimento desse termo na associação livre. 
Quanto às produções das entrevistas, a análise se deu mediante as fases da análise do conteúdo sugeridas por Bardin (2001), resultando em seis categorias, das quais consideramos mais relevante a presença do que a freqüência dos elementos. Por fim, o tratamento das triagens hierarquizadas sucessivas se deu por meio de uma matriz, na qual registramos o número de cada participante, acompanhado de suas respectivas escolhas: as 16, 8, 4, 2, 1 palavras mais características de afetividade.

\section{Resultados e Discussão}

Inicialmente, discutimos os dados provenientes da associação livre. Dentre as 249 evocações, constatamos, no discurso dos participantes, a saliência de alguns termos. A palavra amor foi citada com a maior freqüência (76\%), seguida pelas palavras carinho (75\%), compreensão (52\%), respeito (47\%), amizade (35\%), afeto (26\%), solidariedade (20\%) e atenção (20\%). Como a freqüência apenas não é suficiente para determinar a centralidade de uma representação, inspirando-nos em Vergès (1992), julgamos pertinente combinar a freqüência de emissão das palavras com a ordem na qual elas foram evocadas pelos cem participantes durante a associação livre (Tabela 1). Os quatro quadrantes aí existentes conferem diferentes graus de centralidade aos elementos.

Observamos que as palavras que se situam no quadrante superior esquerdo da Tabela 1, ou seja, amor, carinho, compreensão, respeito, amizade, afeto, solidariedade, atenção e companheirismo são suscetíveis de fazer parte do núcleo central da representação de afetividade, pois, além de apresentarem uma maior freqüência, foram as mais prontamente evocadas pelos participantes. Portanto, a palavra companheirismo - que não apresentava uma freqüência tão expressiva quanto as demais, por ter partilhado de uma ordem média de evocação menor do que 6,61, muda de status. O mesmo não acontece com sua companheira de freqüência, doação, que, com uma média de evocação maior do que 6,61, não partilha do mesmo conjunto a que pertence a palavra companheirismo.

Ao cruzarmos os indicadores freqüência com 42 termo para os participantes da entrevista, ou seja, por meio das triagens hierarquizadas sucessivas, verificamos um consenso em relação à importância das palavras amor e respeito para a representação da afetividade.

Com os resultados precedentes, organizamos um sistema de categorias a partir dos elementos que possuem poder associativo em relação aos demais. Obviamente, esses elementos possibilitam um leque diversificado de agrupamentos e de leituras. Vejamos uma possibilidade de agrupamento para demonstrar o poder organizador dos termos amor: solidariedade, ajuda e doação; respeito: diálogo, valorizar, paciência e sinceridade; carinho: afeto, toque, abraço, ternura e olhar; e amizade: companheirismo, compreensão, atenção, cumplicidade, dedicação, confiança, troca e união.

Os resultados das entrevistas possibilitaram-nos as conclusões:

Primeiro: a afetividade é concebida como um sentimento, um estado e uma ação que se transformam em expressão humana de amor, ternura, proteção, cuidado, respeito, aceitação, amizade e afeição entre as pessoas.

Tabela 1. Os traços salientes das palavras evocadas em relação à afetividade.

\begin{tabular}{|c|c|c|c|c|}
\hline & \multicolumn{4}{|c|}{ Ordem média de evocação } \\
\hline & Palavras & f & Palavras & f \\
\hline \multirow{9}{*}{ 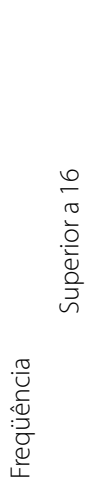 } & Amor & 76 & Doação & 18 \\
\hline & Carinho & 75 & União & 17 \\
\hline & Compreensão & 52 & Dedicação & 17 \\
\hline & Respeito & 47 & & \\
\hline & Amizade & 35 & & \\
\hline & Afeto & 26 & & \\
\hline & Solidariedade & 20 & & \\
\hline & Atenção & 20 & & \\
\hline & Companheirismo & 18 & & \\
\hline \multirow{6}{*}{ 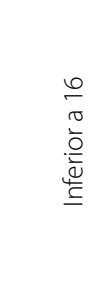 } & Troca & 15 & Tocar & 14 \\
\hline & Ajuda & 11 & Sinceridade & 13 \\
\hline & Olhar & 11 & Diálogo & 11 \\
\hline & Cumplicidade & 11 & Confiança & 11 \\
\hline & Ternura & 11 & Valorizar & 10 \\
\hline & Abraço & 10 & Paciência & 10 \\
\hline
\end{tabular}


Segundo: a afetividade é importante para o ensino e para a aprendizagem na medida em que contribui para a criação de um clima de compreensão, de confiança, de respeito mútuo, de motivação e de amor que podem trazer benefícios para a aprendizagem escolar.

Terceiro: os resultados positivos de uma relação educativa movida pela afetividade opõem-se àqueles apresentados em situações em que existe carência desse componente. Assim, num ambiente afetivo, seguro, os alunos mostram-se calmos e tranqüilos, constroem uma auto-imagem positiva, participam efetivamente das atividades propostas e contribuem para o atendimento dos objetivos educativos. No caso contrário, o aluno rejeita o professor e a disciplina por ele ministrada, perde o interesse em freqüentar a escola, contribuindo para seu fracasso escolar.

Quarto: o professor que possui a competência afetiva é humano, percebe seu aluno em suas múltiplas dimensões, complexidade e totalidade. Nesse caso, o aluno não é considerado um receptáculo de conhecimentos escolares, segundo a concepção bancária de educação (Freire, 1974), mas um sujeito ativo, portador tanto de problemas quanto de potencialidades. Se o aluno vive num meio insalubre, se apresenta carências afetivas e socioeconômicas, é acolhido como sujeito, tocado e valorizado como pessoa com suas idiossincrasias. Os professores parecem, com efeito, preocupados com a aprendizagem e com o sucesso escolar dos seus alunos. Além dessas características intrínsecas à personalidade, o modelo de professor "afetivo" em que se representam os participantes apresenta características profissionais desejáveis, como a capacidade de desenvolver estratégias pedagógicas e educativas dinâmicas e criativas que estimulam o aluno notadamente pelo próprio prazer de ensinar e que envolve os alunos nas decisões e nos trabalhos de grupo. Finalmente, os participantes reivindicam a inclusão da dimensão afetiva nos programas de formação dos professores.

Quinto: os participantes demonstram capacidade para identificar os problemas existentes em sua prática, mas, desprovidos das competências profissionais, tendem a resolvê-los por meio de mecanismos morais e religiosos.
Sexto: em razão dos obstáculos que tornam difícil a ação educativa, é urgente investir na formação profissional dos professores que trabalham no ensino fundamental, no que tange à competência afetiva na relação educativa. Os participantes deixam transparecer, em seu discurso, falta de preparo para o exercício da profissão e reconhecem que, nos programas de formação, não aparece, de forma explícita, preocupação com o desenvolvimento da competência afetiva na relação educativa.

A técnica "triagens hierarquizadas sucessivas", que visava mostrar a organização do conteúdo das representações de afetividade, permitiu, aos participantes, fazerem inferências a partir de palavras que, segundo eles, eram mais características de afetividade. Evidenciamos que o termo amor foi, nesse aspecto, considerado o mais característico, seguido de respeito e doação. As palavras amor e respeito apresentam congruência em relação aos indicadores freqüência, ordem de aparecimento na associação livre e nas triagens hierarquizadas sucessivas. O termo doação, considerado muito importante nas triagens hierarquizadas sucessivas, apresenta uma freqüência 18 no universo lexical. Os termos: acolhida, sensibilidade e valorizar, considerados, por uma parte dos pesquisados, como os mais característicos de afetividade, apresentam uma freqüência relativamente baixa (respectivamente $8 \%, 8 \%$ e $10 \%$ ). O termo doação apresenta a freqüência 18, superior, portanto, à mediana 16. No entanto, ele tem uma média de evocação cuja ordem 8,61 é relativamente baixa em relação à mediana 6,61. Notamos que os termos: acolhida, sensibilidade e valorizar foram considerados, por alguns participantes, como os mais característicos de afetividade, mesmo por aqueles que, no momento da associação livre, não os evocaram. Diante dessas aparentes contradições, retornamos aos dados relativos às entrevistas e ali encontramos as explicações. Os termos mais característicos de afetividade não são considerados, na sua acepção geral, como aparecem num dicionário comum. Os sinônimos de afetividade, nesse caso, são associados à relação educativa na qual os participantes desta pesquisa encontram o sentido do termo. Em relação ao contexto de sala de aula é que os participantes constroem sua versão da realidade. Como se fosse difícil para se abstraírem de sua prática cotidiana, 
éa partir dessa prática que eles "teorizam". Nossa pesquisa confirma, então, que "existe uma relação estreita entre representações e práticas cotidianas" (Vergès, 1989, p.344).

\section{Considerações Finais}

Este estudo nos possibilitou apreender o conteúdo, o sentido e a organização das representações compartilhadas de afetividade dos professores que atuam no ensino fundamental, e obter informações sobre a prática educativa desses profissionais.

Os professores atestam, de forma consensual, que a afetividade é importante para que se estabeleça uma melhor relação educativa entre professores e alunos, favorável, conseqüentemente, à aprendizagem dos conteúdos escolares.

Destacamos, nos discursos, que o quadro de miséria, de promiscuidade e de carência afetiva no qual vive uma parte dos alunos da escola pública, hoje, no Brasil, impõe-se como um desafio para o professor da escola pública, o qual necessita compreender e oferecer a atenção a esses alunos, a fim de Ihes ajudar a progredir no processo de aprendizagem.

As representações dos participantes conduzem a um protótipo ou modelo desejável de professor afetivo: um professor centrado na pessoa do aluno, que compreende suas necessidades e as inclui no planejamento do ensino e que busca desenvolver, na sala de aula, atividades criativas, dinâmicas e que demandam participação, nas quais os alunos, em grupo, aprendem a convivência.

Apesar dessa crucial necessidade, os professores confirmam que os cursos de formação de professores na universidade não atribuem à competência afetiva na relação educativa o devido destaque. A representação positiva em relação à afetividade permite-Ihes sugerir aos formadores a ênfase na construção dessa competência, a fim de que eles possam refletir e rever suas práticas educativas com a pretensão de não contribuírem para a produção do fracasso escolar.

Os professores como atores sociais constroem suas representações a partir do conjunto de idéias, opiniões, informações e crenças presentes no seu contexto sociocultural, de modo que tais representações constituem referência para a prática desenvolvida em sala de aula. Por exemplo,"quando o aluno tem mais idade, é necessário saber ter esse contato, quais são as maneiras de tocar esse aluno, justamente para não Ihe despertar um sentimento de paixão" ou ainda "essa história que quando a gente olha, a gente manifesta desejo, a gente associa imediatamente ao pecado! Eu penso que a Igreja, de certo ponto de vista, a Igreja contribuiu bastante para construir esses valores!". Então, o ato de tocar ou de olhar o aluno na sala de aula, que pode interferir na eficácia do processo educativo, parece condicionado pelas avaliações morais do grupo social.

Finalmente, quanto à organização do conteúdo das representações de afetividade, constatamos que o núcleo central dessas representações pode ser constituído dos elementos: amor, carinho, compreensão, respeito, amizade, afeto, solidariedade, atenção e companheirismo e que esses elementos aglutinadores desempenham um papel importante na relação educativa.

\section{Referências}

Abric, J.-C. (1989). L'étude expérimentale des représentations sociales. In D. Jodelet (Dir.). Les représentations sociales (pp.187-203). Paris: Presses Universitaires de France.

Abric, J.-C. (1997). Les représentations sociales: aspects théoriques. In J.-C. Abric (Dir.). Pratiques sociales et représentations (2.ed., pp.11-37). Paris: Presses Universitaires de France.

Araújo, C. M. M. (1995). Relações interpessoais professor-aluno: uma nova abordagem na compreensão das dificuldades de aprendizagem. Dissertação de mestrado não-publicada, Instituto de Psicologia, Universidade Nacional de Brasília.

Assmann, H. (1998). Reencantar a educação: rumo à sociedade aprendente. Petrópolis: Vozes.

Bardin, L. (2001). L'analyse de contenu (10.ed.). Paris: Presses Universitaires de France.

Brasil. Secretaria de Educação Fundamental. (1999). Referenciais para formação de Professores. Brasília: MEC.

Camargo, D. (1997). As emoções no processo de aprendizagem. Tese de doutorado não-publicada, Pontifícia Universidade Católica de São Paulo.

Cianfa, C. R. L. (1996). A importância das relações interpessoais na educação de adultos. Dissertação de mestrado nãopublicada, Faculdade de Educação, Universidade Estadual de Campinas. 
Codo, W., \& Gazzotti, A. A. (1999). Trabalho e afetividade. In W. Codo (Dir.). Educação, carinho e trabalho (3.ed., pp.4859). Petrópolis: Vozes.

Côté, R. L. (2002). Faire des émotions et de l'affectivité des alliés dans le processus d'enseignement-apprentissage. In L. Lafortune \& P. Mongeau (Dir.). L'affectivité dans l'apprentissage (pp.85-114). Québec: Presses de I'Université du Québec.

Damásio, A. R. (2000). O sentimento de si: a emoção e a neurobiologia da consciência (8.ed.). Lisboa: Publicações Europa-América.

Dias, A. M. S. (2003). O desenvolvimento pessoal do educador através da Biodança. Dissertação de mestrado nãopublicada, Departamento de Éducação, Universidade Federal de Alagoas, Maceió.

Espinosa, G. (2002). La relation ma"tre-élève dans sa dimension affective: un pivot pour une différenciation des pratiques pédagogiques enseignantes? In L. Lafortune \& P. Mongeau (Dir.). L'affectivité dans l'apprentissage (pp.159-181). Québec: Presses de I'Université du Québec.

Freire, P. (1974). Pédagogie des opprimés. Paris: François Maspero.

Hess, R., \&Weigand, G. ( 1994). La relation pédagogique. Paris: Armand Colin.

Lage, E. (2002). Modelos e pesquisas no campo das Representações Sociais. Curso ministrado no Departamento de Ciências da Vida. Salvador: UNEB.

Moll, J. (1999). La dimension affective dans la formation des adultes. In G. Chappaz (Dir.). La dimension affective dans l'apprentissage et la formation (pp.103-130). Paris: SFPUNAPEC.

Moliner, P. (1995). A two-dimensional model of social representations. European Journal of Social Psychology, $25(1), 27-40$
Pereira, T. L. (1991). Comunicação professor e aluno em sala de aula. Dissertação de mestrado não-publicada, Escola de Comunicações e Artes, Universidade de São Paulo.

Ribeiro, M. L. (2004). Une analyse des représentations sociales de l'affectivité chez des enseignants qui participent au programme de formation en enseignement primaire dans une université publique de l'État de Bahia. Tese de doutorado não-publicada, Université de Sherbrooke, Sherbrooke, Canadá.

Rey, F. G. (1995). Comunicación, personalidade y desarrollo. Habana: Editorial Pueblo y Educación.

Rodríguez, J. I., Plax, T. G., \& Kearney, P. (1996). Clarifying the relationship between teacher nonverbal immediacy and student cognitive learning: affective learning as the central causal mediator. Communication Education, 45 (4), 293-305.

Testerman, J. (1996). Holding at-risk students: the secret is one-on-one. Phi Delta Kappan, 77(5), 364-65.

Toro, R. (2002). Biodanza. São Paulo: Editora Olavobrás.

United Nations Educational, Scientific and Cultural Organization. (1992). Principal regional office for Asia and the Pacific. Education for affective development: a guidebook on programs and practices. Bangkok: Unesco.

Vergès, P. (1989). Représentations Sociales de l'économie: une forme de connaissance. In D. Jodelet (Dir.). Les représentations sociales (pp.387-405). Paris: Presses Universitaires de France.

Vergès, P. (1992). L'évocation de l'argent: une méthode pour la définition du noyau central d'une représentation. Bulletin de Psychologie, 45 (405), 203-209.

Recebido em: 5/7/2005

Aprovado em: 5/10/2005 